\title{
Improvement of Gene Expression Studies in the Dimethylnitrosamine Induced Liver Fibrosis Model in the Rat Using Selected Reference Genes for Quantitative Real Time-PCR Analysis
}

\author{
Dinesh Babu Kuppan Rajendran, Phang Gary Siew Siang, Toh Alden Han Hui and Kum Fai Chooi* \\ Technology Development, School of Applied Science, Temasek Polytechnic, 21 Tampines Ave 1, Singapore
}

\begin{abstract}
Background: Liver fibrosis is a reaction to chronic liver injury characterized by excessive accumulation of collagen. Due to their importance as biomarkers, the changes in gene expression in the liver during the development of fibrosis and its subsequent outcomes of cirrhosis, neoplasia or resolution are intensely studied. Quantitative realtime PCR (qPCR) with its ability to detect and measure minute amounts of nucleic acids have been increasingly used in these studies. In qPCR, the quantitation of mRNA is relative and the accuracy of results dependent on the reference genes used for standardization. However, many genes studied are normalized against single reference genes, usually housekeeping genes, without adequate justification.
\end{abstract}

Methods: For the dimethylnitrosamine (DMN) induced liver fibrosis rat model, we tested 8 commonly used candidate genes (Actb, Alb, Sdha, B2m, Rn18s, Hprt1, Ppia and Gapdh) to determine their suitability as reference genes. qPCR results were analysed using four commonly used programs; NormFinder, GeNorm, Comparative $\Delta \mathrm{Ct}$ methods and BestKeeper.

Result: It was determined that Gapdh and B2m were the most stable genes in normal liver. However, in DMN treated livers, Gapdh and Ppia were the most stably expressed reference genes. We validated these reference genes by using them to normalize the expression of four genes; Tgfb 1; Col1a1; Col3a1 and Tnf known to be highly expressed in liver fibrosis.

Conclusion: Gapdh and Ppia are the most suitable reference genes for the normalization of qPCR data in gene expression studies of the liver in the DMN induced liver fibrosis model in the rat. We advise against the use of Actb in this experimental setting because of its low expression stability.

Keywords: DMN; Liver fibrosis; Gene expression; Reference gene; qPCR

\section{Introduction}

Fibrosis of the liver is due to the progressive accumulation of connective tissue caused by various etiologies. The most common causes being infection with hepatitis $\mathrm{B}$ or $\mathrm{C}$ virus, metabolic disorders, alcohol abuse and autoimmune diseases [1]. Fibrosis can lead to cirrhosis, hepatocellular cancer and eventual liver failure [2]. In diseased liver, deposition of the extracellular matrix is mainly due to activated hepatic stellate cells that differentiate into myofibroblasts. These cells also stimulate the inflammatory response and interfere with the normal resorption of ECM [1]. Besides myofibroblasts, different populations of macrophages have also been identified to play critical roles throughout the initiation, maintenance and resolution of liver fibrosis [3]. Thus in this scenario of complex tissue changes and cellular interactions, it is important to measure altered gene expression in a reliable and accurate manner.

Quantitative real-time PCR ( $\mathrm{qPCR}$ ) is a primary tool for studying changes in relative gene expression in different tissues and experimental conditions. This technique is increasingly used because of its high sensitivity, specificity and large dynamic range [4,5]. However, variations in RNA extraction, amount of starting material, enzymatic efficiency and PCR efficiency can lead to quantification errors. Quality assurance and control(s) are essential to obtain consistent and effective gene expression profile [6]. The most widely adopted approach is to use "housekeeping/reference" gene(s) as internal controls for data normalization. A perfect reference gene is one that is expressed constitutively by different tissue types, disease state and experimental conditions [7]. Although these genes are considered to be constitutively expressed, there is usually variation in the level of expression depending on tissue type as well as physiological, pathological and experimental situations. These variations in the reference gene expression, will lead to misinterpretation of data. Thus identification and validation of suitable reference genes for a specific model is crucial to the accuracy of the gene expression pattern $[8,9]$. In preclinical studies, many groups have used animal models as part of experimental liver fibrosis research. The different rodent animal models used and the translational aspects were recently reviewed by Liedtke et al. [10]. For rats, these include models made using bile duct ligation, carbon tetrachloride, gene knock-outs and DMN. The DMN model has many features of human liver fibrosis [11-13] and is the one that our group currently uses to test potential antifibrotic compounds. In this model, liver fibrosis is induced by intraperitoneal injections of DMN for 3 consecutive days a week, for a total of 4 weeks. At the end of the 4 th week of DMN administration, animals have typically developed severe fibrosis $[14,15]$. We recognise that for

*Corresponding author: Kum Fai Chooi, Technology Development, School of Applied Science, Temasek Polytechnic, 21 Tampines Ave 1, Singapore, Tel: +65 6780 6207; E-mail: chooikf@tp.edu.sg

Received October 24, 2016; Accepted November 04, 2016; Published November 10, 2016

Citation: Rajendran DBK, Phang GSS, Toh AHH, Chooi KF (2016) Improvement of Gene Expression Studies in the Dimethylnitrosamine Induced Liver Fibrosis Model in the Rat Using Selected Reference Genes for Quantitative Real Time-PCR Analysis. J Tissue Sci Eng 7: 183. doi:10.4172/2157-7552.1000183

Copyright: @ 2016 Rajendran DBK, et al. This is an open-access article distributed under the terms of the Creative Commons Attribution License, which permits unrestricted use, distribution, and reproduction in any medium, provided the original author and source are credited. 
Citation: Rajendran DBK, Phang GSS, Toh AHH, Chooi KF (2016) Improvement of Gene Expression Studies in the Dimethylnitrosamine Induced Liver Fibrosis Model in the Rat Using Selected Reference Genes for Quantitative Real Time-PCR Analysis. J Tissue Sci Eng 7: 183. doi:10.4172/2157-7552.1000183

Page 2 of 10

accurate documentation of gene expression in each animal model studied, the reference genes must first be determined.

We reviewed 33 articles $[11,12,14,16-45]$ to identify genes that were used for normalizing gene expression in studies where DMN was used to induce liver fibrosis in the rat. The most commonly used reference genes are Glyceraldehyde-3-phosphate dehydrogenase (Gapdh; 17 times), beta-Actin ( $A c t b ; 7$ times), $18 \mathrm{~S}$ ribosomal RNA ( $R n 18 s ; 5$ times), Cyclophilin A (Ppia; 3 times) and Hypoxanthine phosphoribosyl transferase 1 (Hprt1; 2 times). In addition, we included three other commonly used housekeeping genes for normalizing gene expression in the rat; b-2-microglobulin (B2m), Succinate Dehydrogenase (Sdha) and Albumin (Alb) [46-49]. The 8 selected genes were evaluated using the mathematical algorithms; GeNorm [50], NormFinder [51], Comparative $\Delta \mathrm{Ct}$ method [52] and BestKeeper [53] to determine which of them was the most stable reference gene for this liver fibrosis model.

\section{Materials and Methods}

\section{Animals}

Male Wistar rats, 4 weeks old, were purchased from National University of Singapore, Singapore and acclimatised for a week. All animals were maintained at room temperature of $22 \pm 1^{\circ} \mathrm{C}$, with $12 \mathrm{~h}$ light and $12 \mathrm{~h}$ dark cycles with access to food and water ad libitum. The study protocol was approved by the Institutional Animal Care and Use Committee (IACUC No 201007-28); Temasek Polytechnic, Singapore and all experiments were performed in accordance with the approved guidelines and regulations.

\section{Induction and assessment of liver fibrosis}

Liver fibrosis was induced by intra peritoneal (i.p.) injections of dimethylnitrosamine $(\mathrm{DMN})$ into rats $(\mathrm{n}=5)$ at a dose of $10 \mathrm{mg} /$ $\mathrm{kg}$ body weight. Injections were carried out for 3 consecutive days each week over a 4 week period. Control rats $(n=5)$ were injected with $0.9 \%$ physiological saline. Blood was collected three times from the tail vein of all animals for serum biochemical analysis of alanine aminotransferase enzyme (ALT). The first collection was done prior to DMN administration, whilst the second collection was done after 2 weeks of DMN treatment. At the end of the 4 th week, the third blood collection was performed and the rats were euthanized. Complete post mortem examination was performed. Portions of liver were collected and stored in $-80^{\circ} \mathrm{C}$ for gene expression analysis and fixed in $10 \%$ buffered formalin for histopathological analysis. $5 \mu \mathrm{m}$ thick paraffin sections stained with Masson trichrome $[54,55]$ were examined by a pathologist and the degree of fibrosis determined using the Ishak score [56]. In the Ishak score, the severity of fibrosis is ranked from 0 to 6 , with 0 corresponding to no fibrosis and 6 indicating the most severe fibrosis, also referred to as cirrhosis. In summary; 0: No fibrosis, 1 : Fibrous expansion of some portal areas, with or without short fibrous septa, 2: Fibrous expansion of most portal areas, with or without short fibrous septa, 3: Fibrous expansion of most portal areas, occasional portal to portal (P-P) bridging, 4: Fibrous expansion of portal areas with marked bridging (portal to portal (P-P) as well as portal to central (P-C), 5: Marked bridging (P-P and/or P-C) with occasional nodules (incomplete cirrhosis), 6: Cirrhosis, probable or definite.

\section{RNA extraction and cDNA synthesis}

The liver specimens were homogenised and total RNA was extracted using miRNeasy Mini kit (Qiagen) according to the instructions of the manufacturer. The RNA concentration and purity was determined using a nanophotometer (Implen $\mathrm{GmbH}$ ). RNA samples with 260:280 ratio from 1.9 to 2.1 were used for further analysis. RNA samples were stored in $-80^{\circ} \mathrm{C}$ freezer for long term storage or stored in ice for immediate cDNA synthesis. For cDNA synthesis, $2 \mu \mathrm{g}$ of total RNA was reverse transcribed using High Capacity RNA-to-cDNA kit (life technologies). A $20 \mu \mathrm{L}$ reaction mixture containing $1 \mu \mathrm{L}$ of $20 \mathrm{X}$ RT Enzyme mix, $10 \mu \mathrm{L}$ of $2 \mathrm{X}$ RT Buffer, $2 \mu \mathrm{g}$ of RNA sample and nuclease free water was added. The reaction mixture was incubated for $60 \mathrm{~min}$ at $37^{\circ} \mathrm{C}$ and the reaction was terminated by heating to $95^{\circ} \mathrm{C}$ for $5 \mathrm{~min}$. The cDNA was stored at $-20^{\circ} \mathrm{C}$ until the RT-PCR experiments.

\section{Reference gene selection and primer design}

We searched the literature for articles on gene expression where DMN was used to induce liver fibrosis in the rat. We also scanned the literature for other commonly used housekeeping genes in the rat. A list of eight most commonly used reference genes was identified. They were $18 \mathrm{~S}$ Ribosomal protein (Rn18s), Albumin (Alb), b-2microglobulin (B2m), Cyclophilin A (Ppia), Glyceraldehyde-3phosphate dehydrogenase (Gapdh), Hypoxanthine phosphoribosyl transferase1 (Hprt1), Succinate dehydrogenase (Sdha) and beta Actin (Actb). The primer for Actb was designed based on available sequences using the Primer3 software.. Primers for Alb, B2m, Ppia, Gapdh, Hprt1, $R n 18 s$ and $S d h a$ were obtained from the literature [46,57]. The primers are listed in Table 1.

\begin{tabular}{|c|c|c|c|c|c|c|}
\hline $\begin{array}{l}\text { Gene } \\
\text { Symbol }\end{array}$ & Gene Name & Gene Function & Primer & $\begin{array}{l}\text { Product } \\
\text { Size (bp) }\end{array}$ & $\begin{array}{l}\text { Efficiency } \\
(\%)\end{array}$ & $\begin{array}{c}\text { Correlation } \\
\text { Coefficient }\left(R^{2}\right)\end{array}$ \\
\hline \multirow{2}{*}{ Rn18s } & \multirow{2}{*}{ 18S Ribosomal RNA } & \multirow{2}{*}{ Protein Synthesis } & F: GTAACCCGTTGAACCCCATT & \multirow{2}{*}{151} & \multirow{2}{*}{90.4} & \multirow{2}{*}{0.996} \\
\hline & & & R: CGCTACTACCGATTGGATGG & & & \\
\hline \multirow{2}{*}{ Alb } & \multirow{2}{*}{ Albumin } & \multirow{2}{*}{ Major plasma protein } & F: GATGCCGTGAAAGAGAAAGC & \multirow{2}{*}{196} & \multirow{2}{*}{81.5} & \multirow{2}{*}{0.997} \\
\hline & & & R: CGTGACAGCACTCCTTGTTG & & & \\
\hline \multirow{2}{*}{ B2m } & \multirow{2}{*}{ Beta 2 Microglobulin } & \multirow{2}{*}{$\begin{array}{c}\text { Beta-chain of major } \\
\text { histocompatibility complex }\end{array}$} & F: ACATCCTGGCTCACACTGAA & \multirow{2}{*}{109} & \multirow{2}{*}{92.6} & \multirow{2}{*}{0.998} \\
\hline & & & R: ATGTCTCGGTCCCAGGTG & & & \\
\hline \multirow{2}{*}{ Ppia } & \multirow{2}{*}{ Cyclophilin A } & \multirow{2}{*}{$\begin{array}{c}\text { Serine-threonine } \\
\text { phosphatase inhibitor }\end{array}$} & F: AGCACTGGGGAGAAAGGATT & \multirow{2}{*}{248} & \multirow{2}{*}{90.6} & \multirow{2}{*}{0.995} \\
\hline & & & R: AGCCACTCAGTCTTGGCAGT & & & \\
\hline \multirow{2}{*}{ Gapdh } & \multirow{2}{*}{$\begin{array}{c}\text { Glyceraldehyde 3- } \\
\text { Phosphate Dehydrogenase }\end{array}$} & \multirow{2}{*}{ Glycolysis pathway enzyme } & F: GTATCGGACGCCTGGTTAC & \multirow{2}{*}{128} & \multirow{2}{*}{92.1} & \multirow{2}{*}{0.995} \\
\hline & & & R: CTTGCCGTGGGTAGAGTCAT & & & \\
\hline Hprt1 & $\begin{array}{l}\text { Hypoxanthine Phosphoribosyl } \\
\text { Transferase } 1\end{array}$ & Metabolic salvage of purines & $\begin{array}{l}\text { F: GCTGAAGATTTGGAAAAGGTG } \\
\text { R: AATCCAGCAGGTCAGCAAAGG }\end{array}$ & 157 & 93.8 & 0.994 \\
\hline \multirow{2}{*}{ Sdha } & \multirow{2}{*}{ Succinate Dehydrogenase } & \multirow{2}{*}{ TCA pathway enzyme } & F: AGACGTTTGACAGGGGAATG & 160 & 934 & 0998 \\
\hline & & & R: TCATCAATCCGCACCTTGTA & 100 & 90.4 & 0.990 \\
\hline Actb & Beta Actin & Cytoskeletal structural protein & F: AGCCATGTACGTAGCCATCC & 228 & 108.2 & 0.995 \\
\hline ACtD & Dela Acin & cytoskeletal structural proiem & R: CTCTCAGCTGTGGTGGTGAA & $2 \angle 0$ & 100.2 & 0.990 \\
\hline
\end{tabular}

Table 1: Reference gene primers: Primer information for the eight candidate reference genes. 
Citation: Rajendran DBK, Phang GSS, Toh AHH, Chooi KF (2016) Improvement of Gene Expression Studies in the Dimethylnitrosamine Induced Liver Fibrosis Model in the Rat Using Selected Reference Genes for Quantitative Real Time-PCR Analysis. J Tissue Sci Eng 7: 183. doi:10.4172/2157-7552.1000183

\section{Quantitative real-time PCR}

The PCR reactions were performed on a Rotor Gene Q machine (Qiagen). The reactions were run in triplicates with $2 \mu \mathrm{L}$ of primer pairs, $5 \mu \mathrm{L}$ of SYBR green master mix, $1 \mu \mathrm{L}$ of RNA-free water and $2 \mu \mathrm{L}$ of cDNA template. The PCR was carried out with the following conditions: initial denaturation at $95^{\circ} \mathrm{C}$ for $10 \mathrm{~min}$ followed by 40 cycles of denaturation at $95^{\circ} \mathrm{C}$ for $10 \mathrm{~s}$, annealing and extension together at $60^{\circ} \mathrm{C}$ for $45 \mathrm{~s}$. After the last cycle the melting curve was determined in the range $60-95^{\circ} \mathrm{C}$. Negative control samples were always included in the amplification reactions to check for contamination. Specificity of amplification was confirmed by melting curve analysis.

\section{Determination of reference gene expression stability}

All cDNA samples were normalized at the RNA level. Raw qRTPCR amplification data were exported from Rotor Gene Q Series Software 2.0.2 (Qiagen) to Microsoft Excel. The software LinRegPCR [58] was used to calculate the efficiencies for all the reactions separately. LinRegPCR is a free software tool that uses non-baseline corrected data to perform a baseline correction on each sample separately, then determine a window-of-linearity and then uses linear regression analysis to fit a straight line through the PCR data set. From the slope of this line the PCR efficiency of each individual sample is calculated. The efficiency corrected Ct-values were used in BestKeeper, NormFinder, GeNorm and RefFinder (comparative $\Delta \mathrm{Ct}$ method) to rank the stabilities of the candidate reference genes firstly in livers from control and secondly in livers from both control and DMN treated animals. Besides the stability ranking made by each of the four algorithms, recommended comprehensive stability rankings of the candidate genes in control and control plus DMN treated rats were generated using RefFinder [59].

\section{Validation of reference genes}

The expression pattern of four genes, Tgfb 1, Colla1, Col3a1 and Tnf were analysed using different normalisation strategies. This included applying the most stable reference genes identified from the above software, singly or in combination, to the gene expression data using REST 2009 software (Qiagen) [60]. In addition, the commonly used housekeeping gene, $A c t b$, which was determined to be the least stable, was also tested on the same data set to evaluate the expression pattern of the four genes. The primers for the above target genes are shown in Table 2.

\section{Results}

\section{Assessment of liver fibrosis}

ALT levels were significantly elevated after 2 and 4 weeks of DMN administration (Figure 1). At sacrifice, after 4 weeks of DMN administration, the average fibrosis score for DMN treated rats was 5 out of a maximum of 6 based on the Ishak score (Table 3) [56]. There was marked bridging of portal to portal areas with occasional nodule

\begin{tabular}{|c|c|c|}
\hline Primer & \multicolumn{1}{|c|}{ Primer Sequence 5' $\boldsymbol{\rightarrow}$ 3' } & Product Size (bp) \\
\hline Tgfb 1 & $\begin{array}{l}\text { F: ATACGCCTGAGTGGCTGTCT } \\
\text { R: TGGGACTGATCCCATTGATT }\end{array}$ & 153 \\
\hline Col1a1 & $\begin{array}{l}\text { F: GAGAGCATGACCGATGGATT } \\
\text { R: TTGAGGTTGCCAGTCTGTTG }\end{array}$ & 173 \\
\hline Col3a1 & $\begin{array}{l}\text { F: GTCCACGAGGTGACAAAGGT } \\
\text { R: CATCTTTTCCAGGAGGTCCA }\end{array}$ & 189 \\
\hline Tnf & $\begin{array}{l}\text { F: TGATCCGAGATGTGGAACTG } \\
\text { R: CCCATTTGGGAACTTCTCCT }\end{array}$ & 185 \\
\hline
\end{tabular}

Table 2: Primer set for target genes: Primer information for the selected target genes.

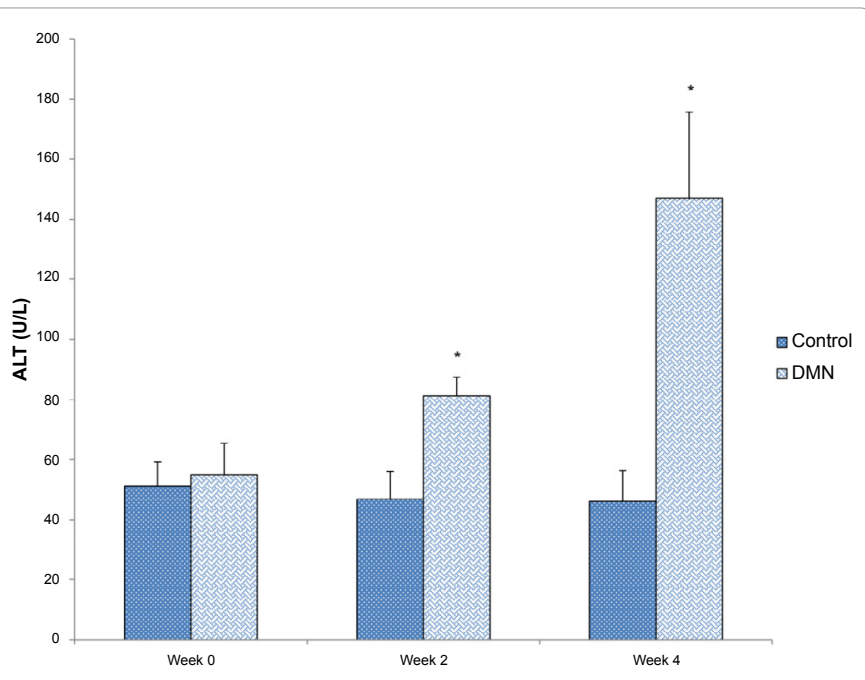

Figure 1: Assessment of liver damage by serum alanine aminotransferase (ALT) level. Serum alanine aminotransferase (ALT) of DMN treated rats at weeks 0,2 and 4 after the last DMN injection. The data are represented as the means $\pm S D(n=6-8)$. ${ }^{*} P<0.05$ compared with normal control group. ALT levels in DMN treated rats were significantly elevated after 2 and 4 weeks of treatment when compared to control rats.

\begin{tabular}{|c|c|}
\hline \multicolumn{2}{|c|}{ Fibrosis score (Using Ishak Score) } \\
\hline $\operatorname{DMN}(n=5)$ & Control $(n=5)$ \\
\hline $5.2 \pm 0.8$ & $0 \pm 0.0$ \\
\hline
\end{tabular}

Table 3: Severity of fibrosis in the liver represented as fibrosis score.
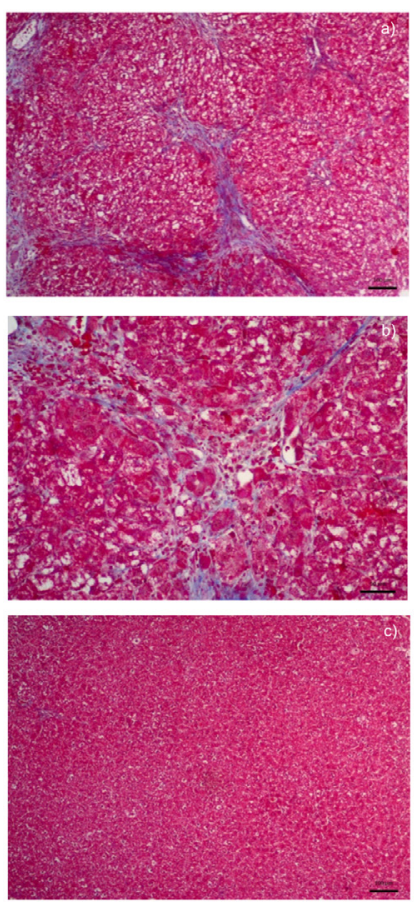

Figure 2: Evaluation of liver fibrosis by histopathological examination. Photomicrographs of Masson's Trichrome stained sections of livers from rats. Liver section from a rat after receiving 4 weeks of DMN, (a) 40X magnification, and (b) 100X magnification. There is fibrous expansion of portal areas with marked portal to portal as well as portal to central bridging, with nodular formation (a). Collagen strands (stained blue) are present in between hepatic cords and separating hepatocytes (b). Liver section from a normal control rat, (c) 40X magnification 
Citation: Rajendran DBK, Phang GSS, Toh AHH, Chooi KF (2016) Improvement of Gene Expression Studies in the Dimethylnitrosamine Induced Liver Fibrosis Model in the Rat Using Selected Reference Genes for Quantitative Real Time-PCR Analysis. J Tissue Sci Eng 7: 183. doi:10.4172/2157-7552.1000183

Page 4 of 10

formation (Figure 2a). At higher magnification, collagen strands were visible between hepatic cells, some of which were necrotic (Figure $2 b$ ). The fibrosis score for control rats was 0 (Figure 2c).

\section{Amplification efficiency}

The amplification efficiency for all qRT-PCR reactions was calculated using the LinRegPCR software. The results were included in Table 1. The PCR amplification efficiency for each reference gene ranged from 90.2 to $108.2 \%$, with the exception of Alb which showed an efficiency of $81.5 \%$. The amplification performance of each primer was verified by RT-PCR and primer specificity was tested by melting curve analysis. The linear regression coefficient for all candidate reference genes ranged between 0.994 and 0.998 .

\section{Gene expression levels of candidate reference genes}

The expression level of all reference genes were calculated using threshold cycle $(\mathrm{Ct})$ values for two groups; control and DMN treated rats. The transcription differences were shown in the box plot of $\mathrm{Ct}$ values (Figure $3 \mathrm{a}$ ) for control rats and Figure $3 \mathrm{~b}$ for DMN treated rats. For the control group, the SD for Ct values of all genes were within a narrow range; 0.46 to 0.87 . For DMN treated rats, the SD range was wider, ranging from 1.09 to 1.85 for all genes except $18 \mathrm{~s}$ (Table 4).

Analysis of reference gene stability using NormFinder, GeNorm, Comparative $\Delta \mathrm{Ct}$ method and BestKeeper. The Ct data from the two groups; control and control plus DMN treated rats were analysed using four different algorithms. NormFinder calculates the stability value for each reference gene and inter and intragroup variation between treated and untreated samples. The candidate gene with the lowest intergroup variation combined with the lowest average intragroup variation and the lowest stability value would be the most stable housekeeping gene. For control rats, NormFinder analysis showed that Gapdh and B2m with stability values (S) of 0.19 and 0.2 (Figure $4 a$ ) were the most stable reference genes. However, when data from the control plus DMN treated rats, were analysed, Gapdh and Ppia with S values of 0.81 and 0.83 , respectively were the most stable reference genes (Figure 5a). Actb and $A l b$ were found to be the least stable genes for both groups.

GeNorm algorithm calculates the stability measure $(\mathrm{M})$ for a reference gene. Stable expression is indicated by lower values of $M$. The ranking for the reference genes were similar for control and control plus DMN treated groups (Figures $4 \mathrm{~b}$ and 5b). Gapdh and Ppia were the most stable housekeeping genes with identical $M$ values in both groups. Actb and Alb were found to be the least stable genes with $\mathrm{M}$. However, the $M$ values for each reference gene in the control group were lower in the control group than the control plus DMN treated group. GeNorm was also used to determine the optimal number of reference genes required for normalisation. This was done through calculating the pairwise variation $(\mathrm{Vn} / \mathrm{Vn}+1)$ between sequential pairs of candidate reference genes. The value, 0.15 was adopted as the cut-off value to determine the optimal number of reference genes for normalizing the expression of genes of interest. According to GeNorm, three reference genes (Figure 6) would be the optimal number to use for normalization of the current gene expression data.

The Comparative $\Delta \mathrm{Ct}$ method determines the most stable reference gene by comparing the $\mathrm{Ct}$ ratio or relative expression of "pair of genes"

(b)

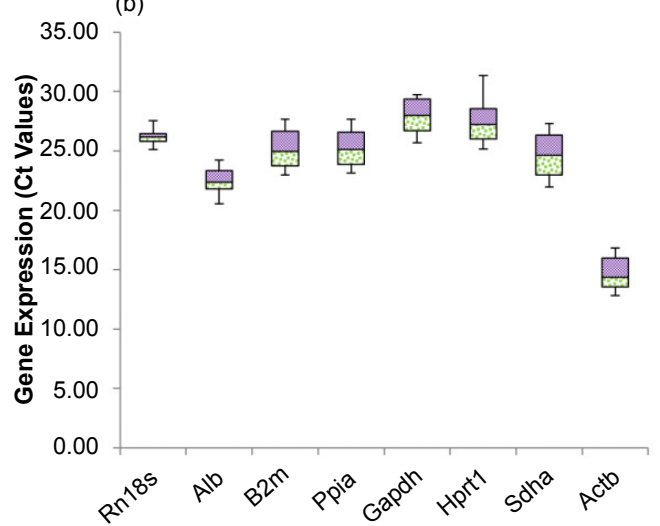

Figure 3: Expression profile of 8 candidate reference genes in rat livers represented as box plots of qPCR (Ct) values. Box plots normal livers; $n=5$ (a) and DMN treated livers; $n=5$ (b). The horizontal line within each box represents the median Ct value and separates the upper and lower quartiles. Vertical lines indicate the range of values. There was lower variation in Ct values of reference genes in control livers compared to those from DMN treated livers.

\begin{tabular}{|c|c|c|}
\hline Gene & & \multicolumn{2}{|c|}{ Liver } \\
\hline Rn18s & Control Average \pm SD & $26.19 \pm 0.57$ \\
\hline $\boldsymbol{A l b}$ & $26.41 \pm 0.64$ & $22.43 \pm 1.09$ \\
\hline B2m & $23.36 \pm 0.49$ & $24.95 \pm 1.60$ \\
\hline Ppia & $23.47 \pm 0.46$ & $25.17 \pm 1.49$ \\
\hline Gapdh & $23.79 \pm 0.47$ & $27.93 \pm 1.51$ \\
\hline Hprt1 & $26.50 \pm 0.50$ & $27.26 \pm 1.52$ \\
\hline Sdha & $26.04 \pm 0.61$ & $24.31 \pm 1.85$ \\
\hline Actb & $22.57 \pm 0.57$ & $14.69 \pm 1.25$ \\
& $15.70 \pm 0.87$ \\
\end{tabular}

Table 4: Average RT-qPCR threshold (Ct) values of 8 reference genes in liver of control and control plus DMN treated rats. Average standard deviation (SD) was calculated from 5 animals in each group, with 3 replicates from each sample $(n=15)$. 
Citation: Rajendran DBK, Phang GSS, Toh AHH, Chooi KF (2016) Improvement of Gene Expression Studies in the Dimethylnitrosamine Induced Liver Fibrosis Model in the Rat Using Selected Reference Genes for Quantitative Real Time-PCR Analysis. J Tissue Sci Eng 7: 183. doi:10.4172/2157-7552.1000183

(a)

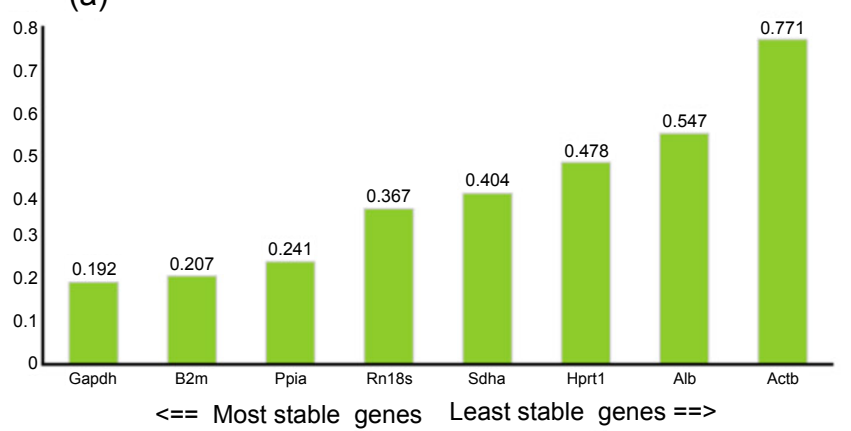

(c)

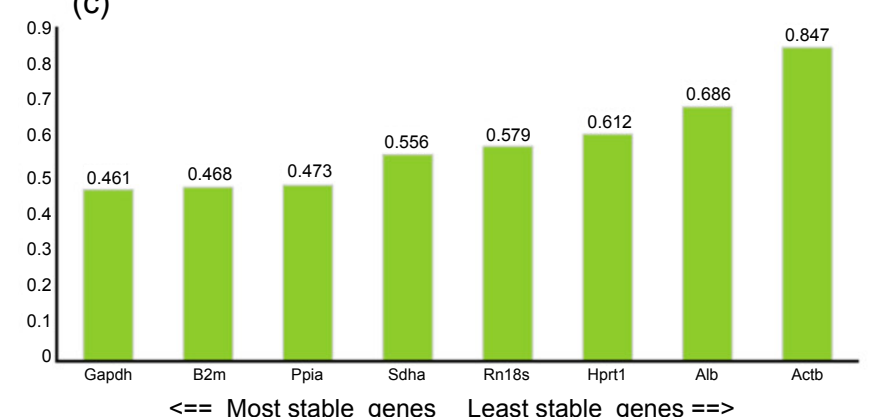

(b)

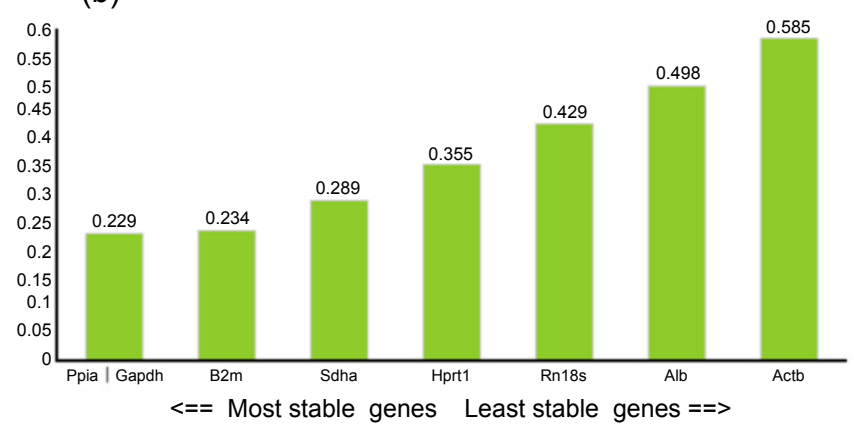

(d)

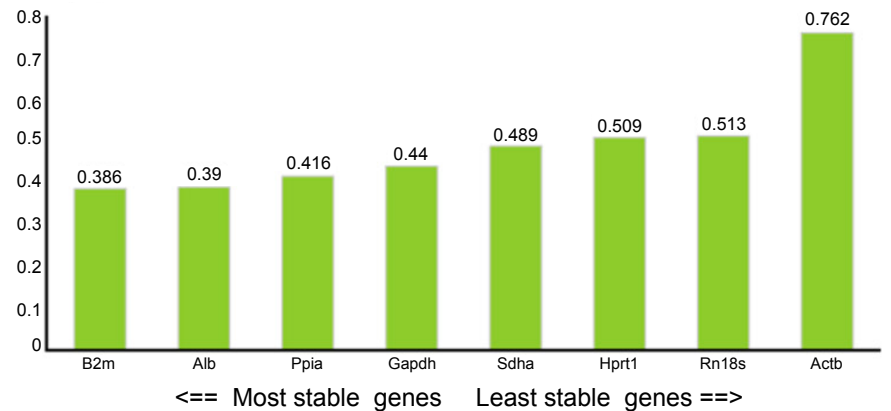

Figure 4: Expression stability of 8 candidate reference genes in normal (control) livers calculated by 4 algorithms. (a) NormFinder (b) GeNorm (c) Comparative $\Delta$ Ct method and (d) BestKeeper. For all algorithms, lower values indicate more stable genes. The genes with the lowest values are most suitable as reference genes.

(a)

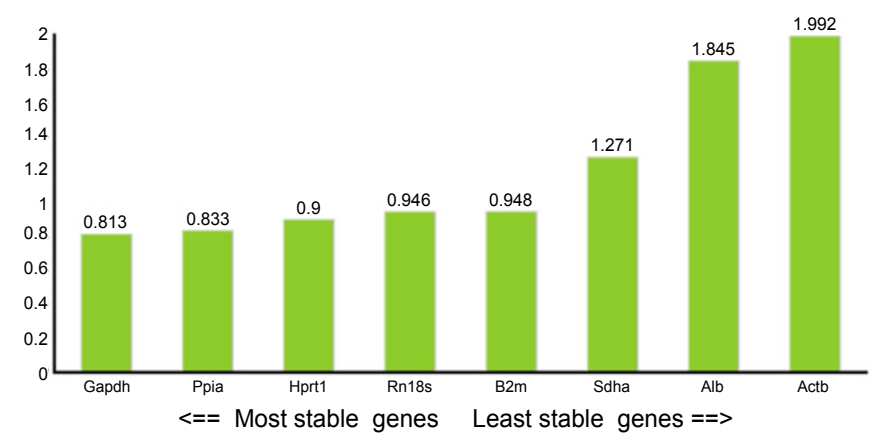

(c)

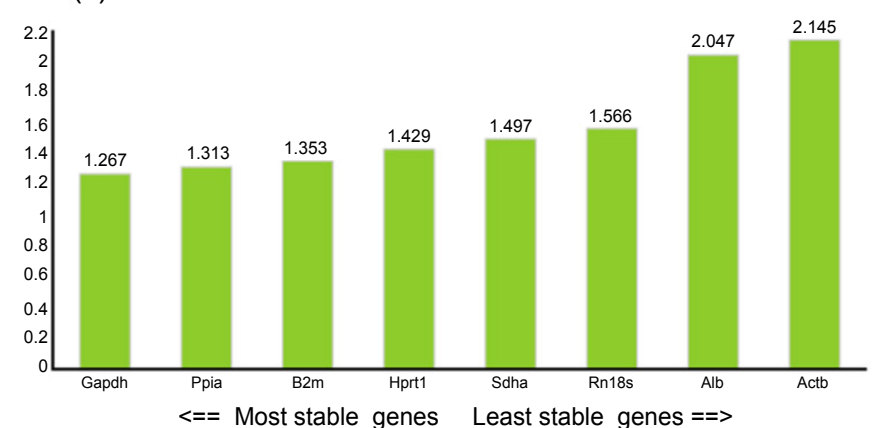

(b)

Gene stability by Genorm

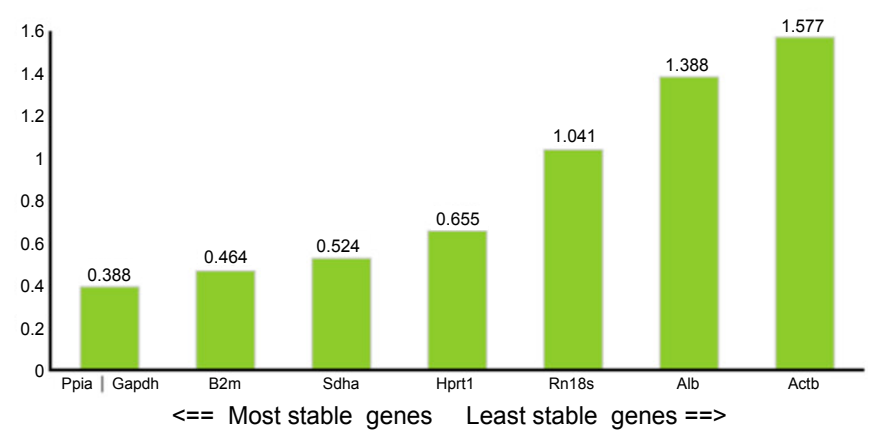

(d)

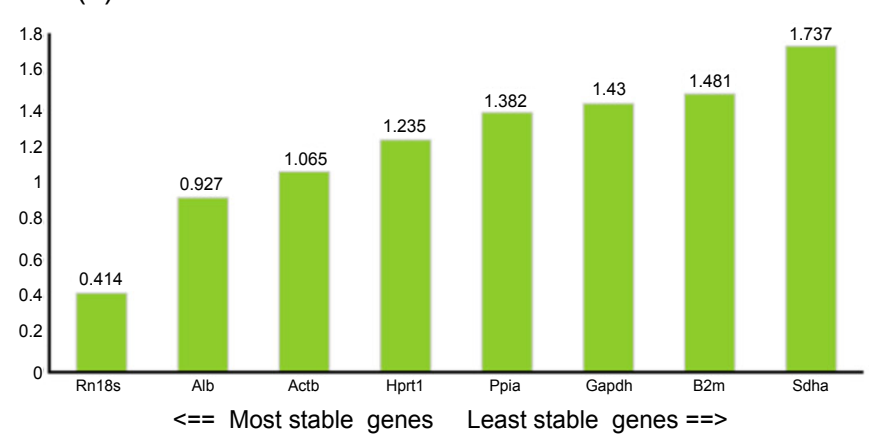

Figure 5: Expression stability of 8 candidate reference genes in all livers (normal and DMN treated) calculated by 4 algorithms. (a) NormFinder (b) GeNorm (c) Comparative $\Delta \mathrm{Ct}$ method and (d) BestKeeper. For all algorithms, lower values indicate more stable genes. The gene with the lowest value is the most suitable reference gene whilst the gene with the highest value is the most unsuitable reference gene. 
Citation: Rajendran DBK, Phang GSS, Toh AHH, Chooi KF (2016) Improvement of Gene Expression Studies in the Dimethylnitrosamine Induced Liver Fibrosis Model in the Rat Using Selected Reference Genes for Quantitative Real Time-PCR Analysis. J Tissue Sci Eng 7: 183. doi:10.4172/2157-7552.1000183

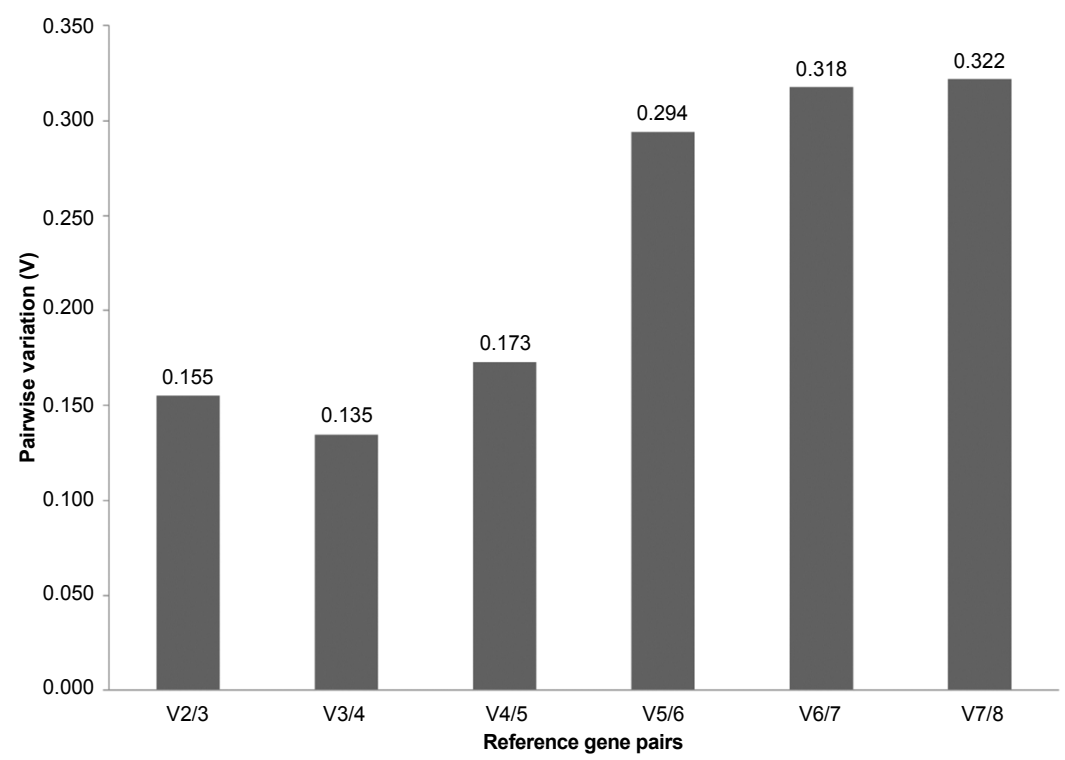

Figure 6: Determination of the optimal number of reference genes for normalization by GeNorm. GeNorm was used to calculate the pairwise variation (V) to determine the optimal number of reference genes required for normalization of qRT-PCR gene expression based on the cut-off value 0.15 . As the reference gene pair of $V 3 / 4$ exhibited the value of 0.135 , this indicates that 3 reference genes are recommended for normalization of the qRT-PCR data.

\begin{tabular}{|c|c|c|c|c|c|}
\hline Stability Order & Normfinder & Genorm & Delta CT & BestKeeper & $\begin{array}{c}\text { Recommended } \\
\text { comprehensive ranking }\end{array}$ \\
\hline 1 & Gapdh & Ppia|Gapdh & Gapdh & $B 2 m$ & Gapdh \\
\hline 2 & $B 2 m$ & & $B 2 m$ & $A l b$ & $B 2 m$ \\
\hline 3 & Ppia & $B 2 m$ & Ppia & Ppia & Ppia \\
\hline 4 & Rn18s & Sdha & Sdha & Gapdh & Sdha \\
\hline 5 & Sdha & Hprt1 & Rn18s & Sdha & $A / b$ \\
\hline 6 & Hprt1 & Rn18s & Hprt1 & Hprt1 & Rn18s \\
\hline 7 & $A / b$ & $A l b$ & $A / b$ & Rn18s & Hprt1 \\
\hline 8 & Actb & Actb & Actb & Actb & Actb \\
\hline
\end{tabular}

Table 5a: Ranking of reference gene based on each program and recommended comprehensive ranking. Gene stability based on livers from control animals ( $\mathrm{n}=5$, with 3 replicates each making total of 15 data sets)

\begin{tabular}{|c|c|c|c|c|c|}
\hline Stability Order & Normfinder & Genorm & Delta CT & BestKeeper & $\begin{array}{c}\text { Recommended } \\
\text { comprehensive ranking }\end{array}$ \\
\hline 1 & Gapdh & Ppia|Gapdh & Gapdh & Rn18s & Gapdh \\
\hline 2 & Ppia & & Ppia & $A / b$ & Ppia \\
\hline 3 & Hprt1 & $B 2 m$ & $B 2 m$ & Actb & Rn18s \\
\hline 4 & Rn18s & Sdha & Hprt1 & Hprt1 & Hprt1 \\
\hline 5 & $B 2 m$ & Hprt1 & Sdha & Ppia & $B 2 m$ \\
\hline 6 & Sdha & Rn18s & Rn18s & Gapdh & $A l b$ \\
\hline 7 & $A l b$ & Alb & $A / b$ & $B 2 m$ & Sdha \\
\hline 8 & Actb & Actb & Actb & Sdha & Actb \\
\hline
\end{tabular}

Table 5b: Gene stability based on livers from control and DMN treated animals $(n=10$, with 3 replicates each making total of 30 data sets).

within each sample and determines the standard deviation of $\Delta \mathrm{Ct}$. The gene with the highest standard deviation of $\Delta \mathrm{Ct}$ is the least stable gene and vice versa. In the control group, Gapdh and $B 2 m$ were the most stable genes (Figure 4c). However, in the control plus DMN treated group, Gapdh and Ppia were identified as the most stable genes. For both groups, $A c t b$ was the least stable gene.

The Microsoft Excel based tool BestKeeper uses raw Ct values as input to determine the stability of reference gene expression. BestKeeper calculates the expression variation based on standard deviation (SD) and Pearson correlation coefficient for each reference gene pair. The program establishes the BestKeeper index which is the geometric mean based on raw $\mathrm{Ct}$ values by pairwise correlation analysis for each reference gene pair.
The most stable reference genes predicted by this program were different from the other three programs used. For the control group, the most stable genes were identified as $B 2 m$ and $A l b$, whereas the least stable genes were $R n 18 s$ and $A c t b$ (Figure 4d). For the control plus DMN treated group, this program indicated that $R n 18 s$ and $A l b$ were the most stable genes whereas the least stable genes were $B 2 m$ and $S d h a$ (Figure $5 \mathrm{~d}$ ).

The $\mathrm{Ct}$ values were further analysed using RefFinder and the recommended comprehensive ranking for the most stable reference genes were Gapdh and $B 2 m$ for the control group. The least stable genes for this group were Hprt1 and Actb (Table 5a). For the control plus DMN treated group, the most stable genes were Gapdh and Ppia whereas the least stable genes were $S d h a$ and $A c t b$ (Table 5b). 
Citation: Rajendran DBK, Phang GSS, Toh AHH, Chooi KF (2016) Improvement of Gene Expression Studies in the Dimethylnitrosamine Induced Liver Fibrosis Model in the Rat Using Selected Reference Genes for Quantitative Real Time-PCR Analysis. J Tissue Sci Eng 7: 183. doi:10.4172/2157-7552.1000183

Page 7 of 10

\section{Validation of reference genes}

To show the effect of different reference genes on the outcome of an actual experiment, we evaluated the expression pattern of four genes, $T g f b$ 1, Colla1, Col3al and Tnf, in our current experiment, using rat liver tissue after 4 weeks of DMN treatment. Tgfb 1, Col1a1, Col3al and $\operatorname{Tnf}$ were significantly over-expressed when normalised using the most stable reference gene, Gapdh as well as the combinations of 2 (Gapdh and Ppia ) and 3 most stable genes (Gapdh, Ppia and Rn18s). When the least stable gene Actb was used as the normalisation reference gene, the expression of $T g f b 1$ and Collal was low. There was no increase in the expression of Col3a1 and Tnf expression was down-regulated (Figures 6 and 7).

\section{Discussion}

qPCR is a powerful method that combines high specificity and sensitivity for studying mRNA expression level in tissues or cell culture. However, to obtain accurate data, suitable reference gene(s) must be used for normalization of qPCR results $[4,5]$ to ensure that the expression profile of the target gene is not misrepresented. Increasing awareness of the importance of selection of suitable reference genes in preclinical research has led to recent work to identify the least variable housekeeping genes in 11 tissue types in normal rats [49]. In that study nearly two thirds of the 48 mRNA targets showed relatively low expression variability and were considered to be potential reference genes. For normal liver, $B 2 \mathrm{~m}$ was identified to be a suitable reference gene.

We have similarly identified $B 2 m$ to be a suitable reference gene for normal liver, though our results show that it is not the most, but the second most stable gene; after Gapdh.

When the liver is treated with DMN for 4 weeks, the most stable gene remains as Gapdh, but the second most stable is now Ppia. The comprehensive ranking of data from four different algorithms showed that for DMN treated liver, $B 2 m$ was ranked fifth out of eight most stable genes and would not be suitable as a reference gene for this experimental setting. We caution that the most stable genes in normal tissues may not be the same when subjected to experimentation.

From the results of our experiment and from the data presented in the literature, we realise that it is extremely important to state clearly the experimental conditions and tissue types that are being studied using a particular set of reference genes. Svingen et al. used NormFinder to study gene expression data from selected control rat tissues. They analysed data collectively from six tissue types (liver, adrenal, prostate, fat pad, testis and ovaries) of juvenile rats and four tissue types (liver, prostate, fat pad and testis) from adult rats. Out of a total of 12 reference genes tested, they identified Hprt and Sdha as the two most stable reference genes [61]. When they included data from juvenile and adult rats exposed to chemical mixtures in the analysis, Hprt and Sdha remained the most stable genes although they reported the lower ranked genes became more unstable. Thus for their experimental setting, the reference genes for normal and treated tissues were the same.

However, within the same experiment, it should not be assumed that the most stable reference genes determined for the experimental setting and overall group of tissues studied will be the most suitable genes for the study of subsets of tissues from that same experimental setting. In the same study by Svingen et al. the most and least stable reference genes were different when different combinations of normal juvenile tissues were studied. For example, when liver and fat pad were studied together, $B 2 m$ and $T b p$ were the most and least stable genes. However, when prostate and fat pad were studied together, Rps29 and $A c t b$ were the most and least stable genes. Thus their data showed that Hprt could be used as the most suitable reference gene when they compared gene expression across all the different tissue types and chemical treatments in their study. However, if they were to compare

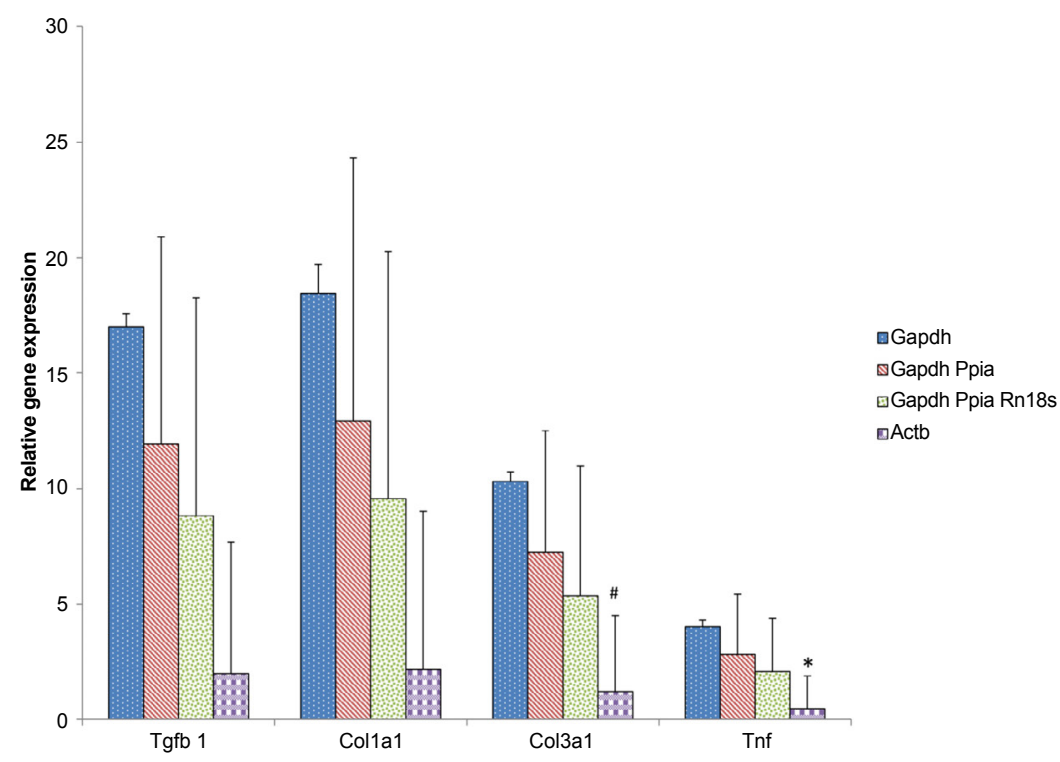

Figure 7: Validation of reference genes using different normalization approaches. Fold expression of Tgfb1, Col1a1, Col3a1 and Tnf genes in the liver of DMN treated rats were normalized (against control rats) with a single most stable, a combination of two and three most stable reference genes and the least stable reference gene. These most stable genes were taken from the comprehensive ranking generated from the 4 algorithms (Table 5b). Tgfb 1, Col1a1, Col3a1 and Tnf were significantly over-expressed when normalised using the most stable reference gene, Gapdh as well as the combinations of 2 (Gapdh and Ppia) and 3 most stable genes (Gapdh, Ppia and Rn18s). When normalisation was done using Actb, the expression of Tgfb 1 and Col1a1 was low. There was no significant increase in the expression of Col3a1 (\#) and Tnf expression was down-regulated $\left({ }^{*}\right)$. For all target genes, the relative gene expression level in control tissues was one. 
Citation: Rajendran DBK, Phang GSS, Toh AHH, Chooi KF (2016) Improvement of Gene Expression Studies in the Dimethylnitrosamine Induced Liver Fibrosis Model in the Rat Using Selected Reference Genes for Quantitative Real Time-PCR Analysis. J Tissue Sci Eng 7: 183. doi:10.4172/2157-7552.1000183

Page 8 of 10

gene expression amongst two specific tissue types, their results would be more accurate if they used the most stable reference gene for those two tissue types and would be highly erroneous if they used Hprt. Hence, it is also important to determine the most stable reference genes for subsets of tissues that are being studied within the overall experimental setting.

All studies on gene expression using the rat DMN model of liver fibrosis reported so far, have used a single non validated endogenous reference gene for normalization of gene expression data $[11,12,45,62]$. The present study is the first to determine suitable reference genes for the DMN model of liver fibrosis in the rat. The development of liver fibrosis in this present experiment was verified by the significantly elevated ALT levels and the fibrosis scores on histopathological examination.

The expression stabilities of eight potential reference genes (Actb, Rn18s, Alb, B2m, Ppia, Gapdh, Hprt1 and Sdha) were analysed using four widely recognized programs (GeNorm, NormFinder, Comparative $\Delta \mathrm{Ct}$ method and BestKeeper). GeNorm uses two parameters; $\mathrm{M}$ (average expression stability) and $\mathrm{V}$ (pairwise variation) to quantify reference gene expression stability. A low $M$ value indicates a more stable expression, hence, increasing the suitability of a particular gene as a reference gene. Other advantages of GeNorm are that it is minimally affected by expression intensity of the candidate genes, does not require a normal distribution of data and, since the approach is based on multiple pair-wise comparisons; a large sample size is not required [50]. The NormFinder algorithm ranks candidate reference genes according to the least estimated intra and inter group variation. NormFinder aims to identify candidate reference genes(s) with an inter group variation as close to zero as possible, while at the same time having small intra-group variation. However, NormFinder is biased towards candidate reference genes that have overall similar $\mathrm{Ct}$ values and the larger the sample size, the more robust the algorithm becomes [51].

The Comparative $\Delta \mathrm{Ct}$ method assesses the most stable RGs by comparing the relative expression of "pairs of genes" within each tissue sample or each treatment, and determines the standard deviation of $\Delta \mathrm{Ct}$. The gene with the highest standard deviation of $\Delta \mathrm{Ct}$ is the least stable gene and vice versa [52]. Unlike GeNorm, NormFinder and Comparative $\Delta \mathrm{Ct}$ methods, input data for analysis by BestKeeper was raw $\mathrm{Ct}$ values of each gene. The overall stability in gene expression is shown by calculated variations in standard deviation (SD), coefficient of correlation $(r)$ and percentage covariance $(\mathrm{CV})$. The lowest $\mathrm{SD}$ value indicates the most stable RG expression [53].

Despite the different mathematical algorithms used by each program, three of these programs, NormFinder, GeNorm and Comparative $\Delta \mathrm{Ct}$ method determined that Gapdh and Ppia were the most suitable reference genes (Table 4). However, the fourth program, BestKeeper identified two other genes; Rn18s and Alb as the most suitable reference genes. The results from GeNorm, NormFinder and the Comparative $\Delta \mathrm{Ct}$ method were more consistent with each other than with the BestKeeper method. This discordance in ranking by the BestKeeper method from the other three alogorithms was similarly made by Chen et al. [63] in their study on gene expression in human umbilical vein endothelial cells.

Both Gapdh and Ppia are genes which control basic, though different cellular functions. Gapdh encodes an enzyme that plays an important role in energy metabolism and production of ATP for glycolysis in the cytoplasm [64]. Ppia encodes a protein which regulates protein folding and trafficking [65]. Our findings that they are the most stable reference genes, suggest that they are not affected in liver cells which undergo changes that result in tissue fibrosis. This was not the case for Actb. Though considered a housekeeping gene leading to its frequent use for normalisation in many types of gene expression studies, including the rat DMN model [12], our study found that Actb was the least stable reference gene. This could be due to the function of the Actb gene which encodes for proteins responsible for cell structure and integrity. Thus we caution against the use of $A c t b$ in this experimental model.

In the present study, the selected reference genes were validated by using them in turn as reference genes to determine the expression of target genes known to be up-regulated in liver fibrosis. These target genes were a) $T g f b 1$, which acts as a central regulator of cell growth and differentiation $[66,67]$, b) Tnf, a cytokine involved in acute phase reactions $[68,69]$ and c) Colla1 and Col3a1, which encode for types I and III pro-collagen respectively $[1,3,70]$.

The most and least stable reference genes and the combination of 2 and 3 most stable reference genes were used for expression normalization. The expression level for the target genes were highest when normalized against the single most stable reference gene (Gapdh) followed by the combinations of 2 (Gapdh and Ppia) and then 3 (Gapdh, Ppia and Rn18s) reference genes. The least stable reference gene (Actb) had the lowest levels of target gene expression.

The use of more than one reference gene normalization can improve the reliability of gene expression studies [71]. The common practice of using one non validated reference gene can lead to erroneous results, as shown in our case, for Actb. One reference gene is suitable to determine "on/off" expression or huge expression differences. This was also true for our case, with Gapdh. According to GeNorm pairwise analysis, the combination of 3 most stable reference genes (Gapdh, Ppia and $R n 18 s)$ were recommended for our data set. However, the target genes' expression levels were higher when normalized against the two most stable genes than against the recommended three most stable genes. Thus, in the DMN model, we believe that two reference genes would be sufficient to determine differences in expression levels of the intended target genes. According to Vandesompele et al. three reference genes could be used to measure small expression differences more reliably [72].

\section{Conclusion}

In conclusion, we used qPCR to obtain data on gene expression patterns of eight candidate reference genes in the liver in the DMN induced model of liver fibrosis in the rat. Analysis of these data by NormFinder, GeNorm, Comparative $\Delta$ Ct Method and BestKeeper programs determined that Gapdh and Ppia were the 2 most suitable reference genes for normalisation in the liver in the rat DMN model of liver fibrosis. The use of these genes as an internal reference gene pair will greatly enhance the reliability and robustness of gene expression data for this experimental model.

\section{Acknowledgement}

This work was supported by grant MOE2012-TIF-2-G-039 from the Ministry of Education, Singapore.

\section{References}

1. Bataller R, Brenner DA (2005) Liver fibrosis. J Clin Invest 115: 209-218.

2. Luedde T, Schwabe RF (2011) NF-kB in the liver-linking injury, fibrosis and hepatocellular carcinoma. Nat Rev Gastroenterol Hepatol 8: 108-118.

3. Wynn TA, Barron L (2010) Macrophages: Master regulators of inflammation and fibrosis. Semin Liver Dis 30: 245-257. 
Citation: Rajendran DBK, Phang GSS, Toh AHH, Chooi KF (2016) Improvement of Gene Expression Studies in the Dimethylnitrosamine Induced Liver Fibrosis Model in the Rat Using Selected Reference Genes for Quantitative Real Time-PCR Analysis. J Tissue Sci Eng 7: 183. doi:10.4172/2157-7552.1000183

Page 9 of 10

4. Kozera B, Rapacz M (2013) Reference genes in real-time PCR. J Appl Genet 54: 391-406.

5. Hruz T, Wyss M, Docquier M, Pfaffl MW, Masanetz S, et al. (2011) RefGenes: Identification of reliable and condition specific reference genes for RT-qPCR data normalization. BMC Genomics 12: 156

6. Setiawan AN, Lokman PM (2010) The use of reference gene selection programs to study the silvering transformation in a freshwater eel Anguilla australis: a cautionary tale. BMC Mol Biol 11: 75

7. Rebouças EDL, Costa JJDN, Passos MJ, Passos JRDS, Hurk R Van Den, et al. (2013) Real time PCR and importance of housekeeping genes for normalization and quantification of mRNA expression in different tissues. Brazilian Arch Biol Technol 56: 143-154.

8. Guénin S, Mauriat M, Pelloux J, Van Wuytswinkel O, Bellini C, et al. (2009) Normalization of qRT-PCR data: The necessity of adopting a systematic experimental conditions-specific, validation of references. J Exp Bot 60: 487493

9. Bustin SA, Benes V, Garson JA, Hellemans J, Huggett J, et al. (2009) The MIQE guidelines: Minimum Information for publication of quantitative real-time PCR experiments. Clin Chem 55: 611-622.

10. Liedtke C, Luedde T, Sauerbruch T, Scholten D, Streetz K, et al. (2013) Experimental liver fibrosis research: Update on animal models, legal issues and translational aspects. Fibrogenesis Tissue Repair 6: 19.

11. Lee HS, Jung KH, Park IS, Kwon SW, Lee DH, et al. (2009) Protective effect of morin on dimethylnitrosamine-induced hepatic fibrosis in rats. Dig Dis Sci 54: 782-788.

12. Shin JW, Son JY, Oh SM, Han SH, Wang JH, et al. (2006) An herbal formula, CGX, exerts hepatotherapeutic effects on dimethylnitrosamine-induced chronic liver injury model in rats. World J Gastroenterol 12: 6142-6148.

13. Wasser S, Tan CEL (1999) Experimental models of hepatic fibrosis in the rat. Ann Acad Med Singapore 28: 109-111.

14. Hsu YC, Lin YL, Chiu YT, Shiao MS, Lee CY, et al. (2005) Anti-fibrotic effects of Salvia miltiorrhiza on dimethylnitrosamine-intoxicated rats. J Biomed Sci 12 : 185-195.

15. Kim HK, Yang TH, Cho HY (2009) Antifibrotic effects of green tea on in vitro and in vivo models of liver fibrosis. World J Gastroenterol 15: 5200-5205.

16. Kang KW, Kim YG, Cho MK, Bae SK, Won CK, et al. (2002) Oltipraz regenerates cirrhotic liver through CCAAT/enhancer binding protein-mediated stellate cell inactivation. FASEB J 16: 1988-1990.

17. de Gouville AC, Boullay V, Krysa G, Pilot J, Brusq JM, et al. (2005) Inhibition of TGF-beta signaling by an ALK5 inhibitor protects rats from dimethylnitrosamineinduced liver fibrosis. Br J Pharmacol 145: 166-177.

18. Lin YL, Hsu YC, Chiu YT, Huang YT (2008) Antifibrotic effects of a herbal combination regimen on hepatic fibrotic rats. Phyther Res 22: 69-76.

19. Gonçalves JO, Tannuri C, Coelho MCM, Bendit I, Tannuri U (2014) Dynamic expression of desmin, a-SMA and TGF-ß1 during hepatic fibrogenesis induced by selective bile duct ligation in young rats. Brazilian J Med Biol Res 47: 850857.

20. Vecera R, Zacharova A, Orolin J, Skottova N, Anzenbacher P (2011) The effect of silymarin on expression of selected $A B C$ transporters in the rat. Vet Med (Praha) 56: 59-62.

21. Ishigaki N, Yamamoto N, Jin H, Uchida K, Terai S, et al. (2009) Continuos intravenous infusion of atrial natriuretic peptide (ANP) prevented liver fibrosis in rat. Biochem Biophys Res Commun 378: 354-359.

22. Lee SJ, Kim YG, Kang KW, Kim CW, Kim SG (2014) Effects of colchicine on liver functions of cirrhotic rats: Beneficial effects result from stellate cell inactivation and inhibition of TGF 31 expression. Chem Biol Interact 147: 9-21.

23. Kang KW, Choi SH, Ha JR, Kim CW, Kim SG (2002) Inhibition of dimethylnitrosamine-induced liver fibrosis by [5-(2-pyrazinyl)-4-methyl-1,2dithiol-3-thione] (oltipraz) in rats: Suppression of transforming growth factor-ß1 and tumor necrosis factor-a expression. Chem Biol Interact 139: 61-77.

24. Sakaida I, Hironaka K, Terai S, Okita K (2003) Gadolinium chloride reverses dimethylnitrosamine (DMN)-induced rat liver fibrosis with increased matrix metalloproteinases (MMPs) of Kupffer cells. Life Sci 72: 943-959.

25. Yang J, Zheng J, Wu L, Shi M, Zhang H, et al. (2011) NDRG2 ameliorates hepatic fibrosis by inhibiting the TGF-î21/Smad pathway and altering the MMP2/TIMP2 ratio in rats. PLoS One 6: e27710.

26. Yin M (2012) Effect of chymase inhibitors on dimethylnitrosamine-induced rat liver fibrosis and on chymase and collagen I expression. African J Pharm Pharmacol 6: 2870-2874.

27. Chong LW, Hsu YC, Chiu YT, Yang KC, Huang YT (2011) Antifibrotic effects of triptolide on hepatic stellate cells and dimethylnitrosamine-intoxicated rats. Phyther Res 25: 990-999.

28. Hong SW, Jung KH, Zheng HM, Lee HS, Suh JK, et al. (2010) The protective effect of resveratrol on dimethylnitrosamine-induced liver fibrosis in rats. Arch Pharm Res 33: 601-609.

29. Kondou H, Mushiake S, Etani Y, Miyoshi Y, Michigami T, et al. (2003) A blocking peptide for transforming growth factor- $\beta 1$ activation prevents hepatic fibrosis in vivo. J Hepatol 39: 742-748.

30. Shin JW, Wang JH, Kang JK, Son CG (2010) Experimental evidence for the protective effects of coffee against liver fibrosis in SD rats. J Sci Food Agric 90: $450-455$

31. Hsu YC, Chiu YT, Cheng CC, Wu CF, Lin YL, et al. (2007) Antifibrotic effects of tetrandrine on hepatic stellate cells and rats with liver fibrosis. J Gastroenterol Hepatol 22: 99-111.

32. Choi JH, Hwang YP, Choi CY, Chung YC, Jeong HG (2010) Anti-fibrotic effects of the anthocyanins isolated from the purple-fleshed sweet potato on hepatic fibrosis induced by dimethylnitrosamine administration in rats. Food Chem Toxicol 48: 3137-3143.

33. Su LJ, Yang CH, Huang SF, Yuo YL, Hsieh HC, et al. (2012) Evaluation of the Chinese medicinal herb, Graptopetalum paraguayense, as a therapeutic treatment for liver damage in rat models. Evidence-Based Complement Altern Med 2012: 1-15

34. Di Sario A, Bendia E, Taffetani S, Omenetti A, Candelaresi C, et al. (2005) Hepatoprotective and antifibrotic effect of a new silybin-phosphatidylcholinevitamin E complex in rats. Dig Liver Dis 37: 869-876.

35. Lee ES, Lee HE, Shin JY, Yoon S, Moon JO (2003) The flavonoid quercetin inhibits dimethylnitrosamine-induced liver damage in rats. J Pharm Pharmacol 55: 1169-1174.

36. Jung KH, Hong SW, Zheng HM, Lee DH, Hong SS (2009) Melatonin downregulates nuclear erythroid 2-related factor 2 and nuclear factor-kappaB during prevention of oxidative liver injury in a dimethylnitrosamine model. $J$ Pineal Res 47: 173-183.

37. Li S, Wang L, Yan X, Wang Q, Tao Y, et al. (2012) Salvianolic acid B attenuates rat hepatic fibrosis via downregulating angiotensin II signaling. Evidence-Based Complement Altern Med 2012: 1-10.

38. Chen JY, Chen HL, Cheng JC, Lin HJ, Tung YT, et al. (2012) A Chinese herbal medicine, Gexia-Zhuyu Tang (GZT), prevents dimethylnitrosamineinduced liver fibrosis through inhibition of hepatic stellate cells proliferation. $J$ Ethnopharmacol 142: 811-818

39. Chong LW, Hsu YC, Chiu YT, Yang KC, Huang YT (2006) Anti-fibrotic effects of thalidomide on hepatic stellate cells and dimethylnitrosamine-intoxicated rats. J Biomed Sci 13: 403-418.

40. Lin HJ, Chen JY, Lin CF, Kao ST, Cheng JC, et al. (2011) Hepatoprotective effects of Yi Guan Jian, an herbal medicine, in rats with dimethylnitrosamineinduced liver fibrosis. J Ethnopharmacol 134: 953-960.

41. Liu C, Sun M, Wang L, Wang G, Chen G, et al. (2008) Effects of Yinchenhao Tang and related decoctions on DMN-induced cirrhosis/fibrosis in rats. Chin Med 3: 1.

42. Di Sario a., Bendia E, Macarri G, Candelaresi C, Taffetani S, et al. (2004) The anti-fibrotic effect of pirfenidone in rat liver fibrosis is mediated by downregulation of procollagen alpha1(I), TIMP-1 and MMP-2. Dig Liver Dis 36: 744-751.

43. Wang JH, Shin JW, Son JY, Cho JH, Son CG (2010) Antifibrotic effects of CGX a traditional herbal formula and its mechanisms in rats. J Ethnopharmacol 127 534-542.

44. Wang Y, Gao J, Zhang D, Zhang J, Ma J, et al. (2010) New insights into the antifibrotic effects of sorafenib on hepatic stellate cells and liver fibrosis. J Hepatol 53: 132-144.

45. Chen X, Liu C, Lu Y, Yang Z, Lv Z, et al. (2012) Paeoniflorin regulates 
Citation: Rajendran DBK, Phang GSS, Toh AHH, Chooi KF (2016) Improvement of Gene Expression Studies in the Dimethylnitrosamine Induced Liver Fibrosis Model in the Rat Using Selected Reference Genes for Quantitative Real Time-PCR Analysis. J Tissue Sci Eng 7: 183. doi:10.4172/2157-7552.1000183

Page 10 of 10

macrophage activation in dimethylnitrosamine-induced liver fibrosis in rats. BMC Complement Altern Med 12: 254

46. Lardizábal MN, Nocito AL, Daniele SM, Ornella LA, Palatnik JF, et al. (2012) Reference genes for real-time PCR quantification of micrornas and messenger RNAs in rat models of hepatotoxicity. PLos One 7: e36323.

47. Verma AS, Shapiro BH (2006) Sex-dependent expression of seven housekeeping genes in rat liver. J Gastroenterol Hepatol 21: 1004-1008.

48. Xing W, Deng M, Zhang J, Huang H, Dirsch O, et al. (2009) Quantitative evaluation and selection of reference genes in a rat model of extended liver resection. J Biomol Tech 20: 109-115.

49. Hong Cai J, Deng S, Kumpf S, Lee P, Zagouras P, et al. (2007) Validation of rat reference genes for improved quantitative gene expression analysis using low density arrays. Biotechniques 42: 503-512.

50. Vandesompele J, De Preter K, Pattyn F, Poppe B, Van Roy N, et al. (2002) Accurate normalization of real-time quantitative RT-PCR data by geometric averaging of multiple internal control genes. Genome Biol 3: 0034

51. Andersen CL, Jensen JL, Ørntoft TF (2004) Normalization of real-time quantitative reverse transcription-PCR data: A model-based variance estimation approach to identify genes suited for normalization, applied to bladder and colon cancer data sets. Cancer Res 64: 5245-5250.

52. Silver N, Best S, Jiang J, Thein SL (2006) Selection of housekeeping genes for gene expression studies in human reticulocytes using real-time PCR. BMC Mol Biol 7:33.

53. Pfaffl MW, Tichopad A, Prgomet C, Neuvians TP (2004) Determination of stable housekeeping genes, differentially regulated target genes and sample integrity: BestKeeper - Excel-based tool using pair-wise correlations. Biotechnol Lett 26 : 509-515.

54. Lendrum AC, Fraser DS, Slidders W, Henderson R (1962) Studies on the character and staining of fibrin. J Clin Pathol 15: 401-413.

55. Silverberg GD, Miller MC, Pascale CL, Caralopoulos IN, Agca Y, et al. (2015) Kaolin-induced chronic hydrocephalus accelerates amyloid deposition and vascular disease in transgenic rats expressing high levels of human APP. Fluids Barriers CNS 12: 2.

56. Ishak K, Baptista A, Bianchi L, Callea F, De Groote J, et al. (1995) Histological grading and staging of chronic hepatitis. J Hepatol 22: 696-699.

57. Kuwahata M, Kubota H, Kanouchi H, Ito S, Ogawa A, et al. (2012) Supplementation with branched-chain amino acids attenuates hepatic apoptosis in rats with chronic liver disease. Nutr Res 32: 522-529.

58. Ramakers C, Ruijter JM, Lekanne Deprez RH, Moorman AFM (2003)
Assumption-free analysis of quantitative real-time polymerase chain reaction (PCR) data. Neurosci Lett 339: 62-66.

59. De Spiegelaere W, Dern-Wieloch J, Weigel R, Schumacher V, Schorle H, et al. (2015) Reference gene validation for RT-qPCR, a note on different available software packages. PLoS One 10: e0122515.

60. Pfaffl MW, Horgan GW, Dempfle L (2002) Relative expression software too (REST) for group-wise comparison and statistical analysis of relative expression results in real-time PCR. Nucleic Acids Res 30: e36.

61. Svingen T, Letting H, Hadrup N, Hass U, Vinggaard AM (2015) Selection of reference genes for quantitative RT-PCR (RT-qPCR) analysis of rat tissues under physiological and toxicological conditions. PeerJ 3:e855.

62. Boers W, Aarrass S, Linthorst C, Pinzani M, Elferink RO, et al. (2006) Transcriptional profiling reveals novel markers of liver fibrogenesis: Gremlin and insulin-like growth factor-binding proteins. J Biol Chem 281: 16289-16295

63. Chen G, Zhao L, Feng J, You G, Sun Q, et al. (2013) Validation of reliable reference genes for real-time PCR in human umbilical vein endothelial cells on substrates with different stiffness. PLoS One 8: e67360.

64. Nicholls C, Li H, Liu JP (2012) GAPDH: A common enzyme with uncommon functions. Clin Exp Pharmacol Physiol 39: 674-679.

65. Wang P, Heitman J (2005) The cyclophilins. Genome Biol 6: 226.

66. Dooley S, ten Dijke P (2012) TGF-ß in progression of liver disease. Cell Tissue Res 347: 245-256.

67. Leask A, Abraham DJ (2004) TGF-beta signaling and the fibrotic response FASEB J 18: 816-827

68. Osawa Y, Hoshi M, Yasuda I, Saibara T, Moriwaki H, et al. (2013) Tumo necrosis factor-a promotes cholestasis-induced liver fibrosis in the mouse through tissue inhibitor of metalloproteinase-1 production in hepatic stellate cells. PLoS One 8: e65251.

69. Wang X, Chen YX, Xu CF, Zhao GN, Huang YX, et al. (1998) Relationship between tumor necrosis factor-alpha and liver fibrosis. World J Gastroentero $4: 18$.

70. Poonkhum R, Pradidarcheep W, Nilbu-Nga S, Chaunchaiyakul S (2011) Distribution of hepatic myofibroblasts and type I and III collagen in rat liver cirrhosis induced by thioacetamide. Int J Morphol 29: 501-508.

71. Matoušková $P$, Bártíková $H$, Boušová I, HanuÅjovÃ $i$ V, SzotÃ $\tilde{A}_{i k o v} \tilde{A}_{i} B$, et al (2014) Reference genes for real-time PCR quantification of messenger RNAs and microRNAs in mouse model of obesity. PLoS One 9: e86033.

72. Vandesompele J, Mikael K, Pfaffl MW (2009) Reference gene validation software for improved normalization. Real-time PCR: Current technology and applications. Canister Academic Press. 